\title{
Aedes Mosquito Distribution along a Transect from Rural to Urban Settings in Yaoundé, Cameroon
}

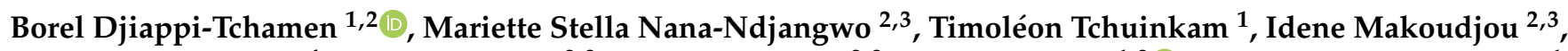 \\ Elysée Nchoutpouen ${ }^{4}$, Edmond Kopya ${ }^{2,3}$, Abdou Talipouo ${ }^{2,3}$, Roland Bamou 1,2(1), Marie Paul Audrey Mayi ${ }^{1}$, \\ Parfait Awono-Ambene ${ }^{2}$, Charles Wondji ${ }^{4,5}$ (-) and Christophe Antonio-Nkondjio ${ }^{2,5, *}$ (i)
}

1 Vector Borne Diseases Laboratory of the Research Unit Biology and Applied Ecology (VBID-RUBAE), Department of Animal Biology, Faculty of Science, University of Dschang, Dschang P.O. Box 067, Cameroon; borel_tchamen@yahoo.com (B.D.-T.); timotchuinkam@yahoo.fr (T.T.); bamou2011@gmail.com (R.B.); mayimariepaulaudrey@yahoo.com (M.P.A.M.)

2 Institut de Recherche de Yaoundé (IRY), Organisation de Coordination pour la Lutte Contre les Endémies en Afrique Centrale (OCEAC), Yaoundé P.O. Box 288, Cameroon; stellanana123@gmail.com (M.S.N.-N.); idenemakoudjou@gmail.com (I.M.); edmondoev@yahoo.fr (E.K.); atalipouo@gmail.com (A.T.); hpaawono@yahoo.fr (P.A.-A.)

3 Department of Animal Physiology and Biology, Faculty of Science, University of Yaoundé I, Yaoundé P.O. Box 337, Cameroon

4 Centre for Research in Infectious Disease (CRID), Yaoundé P.O. Box 13591, Cameroon: enchoutpouen2002@yahoo.fr (E.N.); charles.wondji@lstmed.ac.uk (C.W.)

check for updates

Citation: Djiappi-Tchamen, B.; Nana-Ndjangwo, M.S.; Tchuinkam, T.; Makoudjou, I.; Nchoutpouen, E.; Kopya, E.; Talipouo, A.; Bamou, R.; Mayi, M.P.A.; Awono-Ambene, P.; et al. Aedes Mosquito Distribution along a Transect from Rural to Urban Settings in Yaoundé, Cameroon. Insects 2021, 12, 819. https://doi.org/ $10.3390 /$ insects12090819

Academic Editor: Chelsea T. Smartt

Received: 16 July 2021

Accepted: 7 September 2021

Published: 12 September 2021

Publisher's Note: MDPI stays neutral with regard to jurisdictional claims in published maps and institutional affiliations.

Copyright: (c) 2021 by the authors. Licensee MDPI, Basel, Switzerland. This article is an open access article distributed under the terms and conditions of the Creative Commons Attribution (CC BY) license (https:// creativecommons.org/licenses/by/ $4.0 /)$.
5 Vector Biology Liverpool School of Tropical Medicine Pembroke Place, Liverpool L3 5QA, UK

* Correspondence: antonio_nk@yahoo.fr

Simple Summary: Vector surveillance is key for the prevention of arbovirus disease outbreaks. In the present study, the distribution of the Aedes vector population between the city centre and a close rural setting was assessed. Larval mosquito collections were undertaken from November 2019 to November 2020 along a transect from the rural area to the city centre. All containers with water were inspected. Some entomological indices evaluating transmission risk were estimated. A total of 6332 mosquito larvae were collected. Different Aedes species were recorded, including Ae. albopictus, Ae. aegytpi, Ae. simpsoni and Aedes spp. The density of mosquitoes collected during the rainy season (4706) was high compared to the dry season (1626). Ae. albopictus was the most abundant Aedes species in the urban (96.89\%) and peri-urban (95.09\%) sites while Ae. aegypti was the most abundant species in rural settings $(68.56 \%)$. Ae. Albopictus preferred breeding habitats were discarded tires (42.51\%), whereas Ae. aegypti was more prevalent in plastic containers used for storing water $(65.87 \%)$. High stegomyia indexes traducing a high arbovirus transmission risk were recorded. The study suggests a high frequency of Aedes species in Yaoundé and its neighbourhood and stresses the need for urgent action to control Aedes populations in the city of Yaoundé.

Abstract: Introduction: The surveillance of mosquito vectors is important for the control of arboviruses diseases worldwide. Detailed information on the bionomics and distribution of their main vectors, Aedes aegypti and Aedes albopictus, is essential for assessing disease transmission risk and for better planning of control interventions. Methods: Entomological surveys were carried out from November 2019 to November 2020 in six localities of Yaoundé city following a transect from urban to rural settings: two urban (Obili, Mvan), two peri-urban (Simbock, Ahala) and two rural areas (Lendom, Elig-essomballa)—during rainy and dry seasons. All water containers were inspected. Aedes mosquito abundance, species distribution and seasonal distribution patterns were compared using generalized linear models. Stegomyia indexes were estimated to determine the risk of arbovirus transmission. Results: A total of 6332 mosquitoes larvae were collected (2342 in urban areas, 1694 in peri-urban areas and 2296 in rural sites). Aedes species recorded included Ae. albopictus, Ae. aegytpi, Ae. simpsoni and Aedes spp. High mosquito abundance was registered in the rainy season (4706) compared to the dry season (1626) $(p<0.0001)$. Ae. albopictus was the most abundant Aedes species in urban $(96.89 \%)$ and peri-urban $(95.09 \%)$ sites whereas Ae. aegypti was more prevalent in rural sites $(68.56 \%)(p<0.0001)$. Both species were found together in 71 larval habitats. Ae. albopictus 
was mostly found in discarded tires $(42.51 \%)$, whereas Ae. aegypti was more prevalent in plastic containers used for storing water $(65.87 \%)$. The majority of Aedes mosquitoes' breeding places were situated close to human dwellings $(0-10 \mathrm{~m})$. Conclusion: Uncontrolled urbanization seems to greatly favour the presence of Aedes mosquito species around human dwellings in Yaoundé. Controlling Aedes mosquito distribution is becoming urgent to reduce the risk of arbovirus outbreaks in the city of Yaoundé.

Keywords: Aedes albopictus; Aedes aegypti; rural; peri-urban; urban; breeding site; Yaoundé; Cameroon

\section{Introduction}

Arboviruses pose a serious threat to public health worldwide. Dengue, known as the most widespread arboviral disease, is responsible for more than 90 million cases and approximately 40,000 deaths yearly [1]. Other Aedes borne diseases, including Zika, Chikungunya, yellow fever, Rift Valley fever and West Nile, are also important public health threats [2]. During the last decades, there has been a dramatic resurgence of arboviral diseases around the World [3-6]. As the World responds to repeated outbreaks, surveillance activities and tailored control interventions are desperately needed to protect human populations [7].

The frequency of arbovirus cases could result from the rapid adaptation capacity of their vectors to new environments and viruses to new hosts [8-10]. Furthermore, the current modification of the environment by anthropogenic activities, including the exploitation of lowland area and swamps for farming and/or house construction, the storage of water in containers due to poor water supply in cities, the disposal of domestic wastes close to human habitations and emerging factors related to globalization and climate changes, are all shaping vector populations' expansion ranges and arboviral disease transmission [11-13]. They are then used by Aedes adults females for laying eggs. Such factors are conducive to epidemics in tropical and subtropical areas, especially in sub-Saharan Africa [14].

Enzootic cycles of arboviral diseases are maintained by vectors such as Ae. africanus, Ae. luteocephalus, Ae. simpsoni and Ae. opok, whereas Ae. aegypti and Ae. albopictus are involved in both urban and rural transmission cycles $[15,16]$. Aedes albopictus was reported for the first time in Cameroon in 2001 [14,17], while Ae. aegypti has been reported in the country since the 1950s [18]. Nowadays, Ae. albopictus is well established across the country except in the north and far north regions, and tends to replace the native species, Ae. aegypti, which now predominates in suburban and rural areas [19-24].

Many serological investigations revealed that the number of Dengue, Chikungunya and Zika cases has significantly increased over the last several decades in Cameroon, highlighting the urgent need for a risk assessment of arboviral diseases across the country. Laboratory experiments conducted with Ae. Albopictus populations from Cameroon indicated that the species was competent to transmit Dengue, Yellow fever and Zika virus, as is the native Ae. aegypti [25-27]. In the absence of treatment or vaccines for most of these arboviruses, control efforts rely mainly on vectors control. Continuous surveillance of vector populations is the most reliable method, not only for monitoring vector populations dynamics [28], but also for predicting the transmission risk of arbovirus diseases to human populations [29].

Urbanization could potentially modify Aedes mosquito ecology by changing the composition and dynamics of species and increasing the abundance of their breeding sites through anthropogenic changes [30,31]. Accordingly, understanding the population dynamics and range expansion of vectors is of utmost importance for disease surveillance and control. This study explored the population dynamics of Aedes mosquitoes species and entomological larval indices along a transect from rural to urban areas. It also provides updated information on the distribution of Aedes mosquito species in Yaoundé and its neighbourhood. 


\section{Materials and Methods}

\subsection{Description of Study Sites}

The study was conducted along a transect from urban to rural settings of Yaoundé (Figure 1) and included: two sites in the urban centre, Obili $\left(3^{\circ} 51^{\prime} 26^{\prime \prime} \mathrm{N} ; 11^{\circ} 29^{\prime} 33^{\prime \prime} \mathrm{E}\right)$ and Mvan $\left(3^{\circ} 37^{\prime} 0^{\prime \prime} \mathrm{N} ; 12^{\circ} 18^{\prime} 0^{\prime \prime} \mathrm{E}\right)$; two peri-urban sites, Simbock ( $3^{\circ} 51^{\prime} 24.768^{\prime \prime} \mathrm{N} ; 11^{\circ} 32^{\prime} 52.872^{\prime \prime}$ E) and Ahala ( $\left.3^{\circ} 80^{\prime} 00^{\prime \prime} \mathrm{N} ; 11^{\circ} 48^{\prime} 33^{\prime \prime} \mathrm{E}\right)$; and two rural sites, Lendom $\left(3^{\circ} 57^{\prime} 0^{\prime \prime} \mathrm{N} ; 11^{\circ} 30^{\prime} 0^{\prime \prime}\right.$ E) and Elig-essomballa $\left(11^{\circ} 45^{\prime} 37.90^{\prime \prime} \mathrm{N} ; 3^{\circ} 87^{\prime} 11.75^{\prime \prime} \mathrm{E}\right)$. Yaoundé is located within the Congo-Guinean phytogeographic zone, which is characterized by a typical equatorial climate with four seasons: two rainy seasons (March to June and September to November) and two dry seasons (December to February and July to August) [32]. The city has a population estimated at about 3 million inhabitants and is situated $800 \mathrm{~m}$ above sea level [33]. The landscape of Yaoundé is characterized by an alternation of high and lowland areas frequently used for agricultural practices.

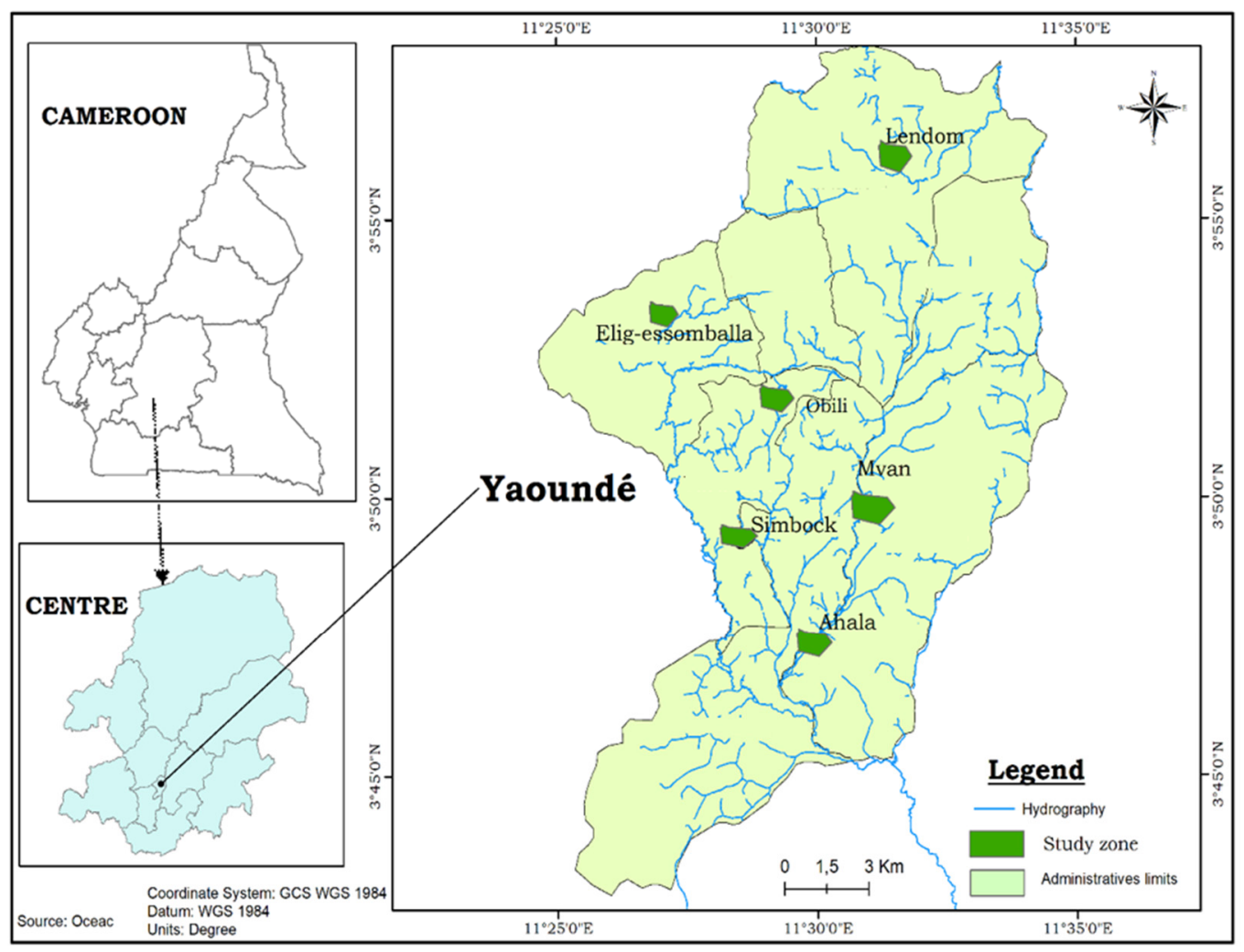

Figure 1. Map of the city of Yaoundé showing the study sites.

In the rural sites, which are Lendom and Elig-essomballa (distance estimated to be $1220.38 \mathrm{~m}$ ), houses were mostly of the traditional style, constructed with mud or wood. These villages are surrounded by a preserved primary rainforest, which provides strong vegetation with dense canopy cover, trees with holes and bamboos. Simbock and Ahala (peri-urban sites separated by $4190.37 \mathrm{~m}$ ), situated at the city's periphery, are characterized by residential buildings with space between houses, large roads and lowland. Obili and Mvan (urban sites, separated by $4304.73 \mathrm{~m}$ ) are densely populated sites characterized by the exploitation of lowland area for house construction with substandard housing. The distance between urban and peri-urban sites was $4734.17 \mathrm{~m}$, and from urban to rural sites it was estimated to be $4216.14 \mathrm{~m}$.

\subsection{Study Design}

Entomological field surveys were conducted from November 2019 to November 2020. During field surveys, oral consent to inspect potential breeding sites was obtained 
from household or garage owners. Aedes immature stages were collected in natural and artificial breeding sites such as tree holes, dead leaves, flower pots, used tires, tanks and abandoned plastic containers. During inspections, each potential breeding place was geo-referenced with a global positioning system (GPS) and, if positive, the following parameters were registered: breeding site type, presence of larval stages, larval instars (L1-L2 or L3-L4), presence of pupae, distance of the breeding sites to the nearest house. Any container with water around houses was considered a breeding habitat. The distance between breeding habitats and houses was estimated. Aquatic habitats were classified according to the following distance ranges from the nearest house: $0-10 \mathrm{~m}, 10-50 \mathrm{~m}$, and $>50 \mathrm{~m}$. Once collected, immature stages from each breeding site were stored in individual plastic containers $(0.5 \mathrm{~L})$ and were brought to the insectary of OCEAC (organization of coordination and fight against the great Endemics in Central Africa) for rearing under controlled conditions (70-80\% humidity, $28 \pm 1{ }^{\circ} \mathrm{C}$ ). After emergence, mosquitoes were provided with $10 \%$ sucrose solution and adults were identified per breeding site under a binocular magnifying glass using morphological identification keys [34,35]. Identified mosquitoes were preserved either in silica gel or in RNA (SIGMA Aldrich, Saint Louis, MO, USA) for further molecular analysis.

Estimation of entomological indices, species richness, and mosquito abundance:

During field surveys, all water containers around houses were inspected in order to detect Aedes larvae and pupae. Different entomological indices were determined, including: House Index (HI) - the percentage of houses found infested with larvae and/or pupae; Container Index (CI) - the percentage of water holding containers with active immature stages; Breteau Index (BI)-the number of positive containers per 100 houses inspected. When $\mathrm{HI}>35 \%, \mathrm{BI}>50$, and $\mathrm{CI}>20 \%$, the area was considered at high risk of yellow fever transmission, whereas areas with $\mathrm{HI}<4 \%, \mathrm{BI}<5$ and $\mathrm{CI}<3 \%$ were considered to be low risk for yellow fever transmission [36]. Similarly, for Dengue transmission risk in a particular area, with a value of $\mathrm{HI}<0.1 \%$, the area is considered low risk; a value of $\mathrm{HI}$ ranging from $0.1 \%-5 \%$ indicated medium risk and $\mathrm{HI}>5 \%$ indicated high risk for Dengue transmission [32]. These indices have been commonly used for risk assessment and served as early warning of Dengue epidemics [34,35]. Species richness (number of species) and mosquito abundance (total number of mosquitoes collected independently of the species) were determined according to habitat type, breeding site type and seasons.

\subsection{Data Analysis}

Statistical analysis was performed using the environment for statistical computing and graphics R version 4.0.4 ("Lost Library Book" Copyright (C) 2021 The R Foundation for Statistical Computing Platform). Species richness (number of species) and mosquito abundance (total number of mosquitoes collected independently of the species) were determined according to habitat type, breeding site type and seasons. Individual-based rarefaction curves for all habitat types across seasons were constructed using the "vegan" package. Generalized Linear Models (GLM) were run (based on a chi-squared distribution using the type III sums of squares method with the package "car") to assess the effect of habitat types (sites), breeding habitats, and seasons on mosquito species' occurrence and distribution. Dunnett's T3 test was used to compare the Container index between sites. The level of significance for statistical analysis was 0.05 .

\section{Results}

\subsection{Mosquito Distribution across Ecological Settings}

A total of 6332 mosquitoes belonging to five genera (Aedes, Culex, Anopheles, Toxorhynchite and Eretmapodites) were collected (Table 1). Out of this number, $2342(36.98 \%)$ were collected at urban sites, $1694(26.75 \%)$ at peri-urban sites and $2296(36.26 \%)$ at rural sites. A total of 5672 Aedes mosquitoes were collected with 4260 (75.10\%) Ae. albopictus, 1314 (23.16\%) Ae. aegypti and 85 (1.49\%) Ae. simpsoni (Table 1). A few of the collected Aedes species $(n=13)$ that could not be identified morphologically were grouped under Aedes spp. 
Ae. albopictus (2214) was present at all sites and represented the most frequent Aedes species in urban $(96.89 \%)$ and peri-urban $(1512 ; 95.09 \%)$ sites, whereas Ae. aegypti was the most common Aedes species in rural areas $(1165 ; 68.56 \%)$. A significant association between Aedes mosquito abundance, species and habitat types was recorded $(p<0.0001)$. A significant association was recorded using GLM when assessing the relationship between mosquito species' distribution vs. sampling sites or season or breeding habitat types (Table 2).

Table 1. Mosquito species identified across the transect from urban, peri-urban and rural areas.

\begin{tabular}{|c|c|c|c|c|c|c|c|}
\hline \multirow{3}{*}{ Species } & \multicolumn{6}{|c|}{ Ecological Zones } & \multirow{3}{*}{ Total } \\
\hline & \multicolumn{2}{|c|}{ Urban } & \multicolumn{2}{|c|}{ Peri-Urban } & \multicolumn{2}{|c|}{ Rural } & \\
\hline & Obili & Mvan & Simbock & Ahala & Lendom & Elig-Essomballa & \\
\hline Ae. albopictus & 459 & 1755 & 1252 & 260 & 295 & 239 & $4260(67.27 \%)$ \\
\hline Ae. aegypti & 3 & 68 & 71 & 7 & 588 & 577 & $1314(20.75 \%)$ \\
\hline Ae. simpsoni & 0 & 0 & 0 & 0 & 65 & 20 & $85(1.34)$ \\
\hline Cx. duttoni & 0 & 21 & 10 & 14 & 103 & 113 & $261(4.12 \%)$ \\
\hline Cx. antennatus & 0 & 0 & 0 & 0 & 26 & 0 & $26(0.41 \%)$ \\
\hline Cx. quinquefasciatus & 0 & 34 & 57 & 0 & 14 & 86 & $191(3.01 \%)$ \\
\hline Lutzia tigripes & 0 & 2 & 1 & 0 & 8 & 9 & $20(0.31 \%)$ \\
\hline Cx. (Culiciomyia) group. & 0 & 0 & 0 & 10 & 91 & 16 & $117(1.84 \%)$ \\
\hline Anopheles funestus & 0 & 0 & 0 & 0 & 0 & 9 & $9(0.14 \%)$ \\
\hline Eretmapodites spp. & 0 & 0 & 0 & 0 & 0 & 15 & $15(0.23 \%)$ \\
\hline Toxorhynchites sp. & 0 & 0 & 0 & 0 & 1 & 0 & $1(0.01 \%)$ \\
\hline Culex spp. & 0 & 0 & 12 & 0 & 2 & 6 & $20(0.31 \%)$ \\
\hline Aedes spp. & 0 & 0 & 0 & 0 & 13 & 0 & $13(0.20 \%)$ \\
\hline Total & 462 & 1880 & 1403 & 291 & 1206 & 1090 & 6332 \\
\hline
\end{tabular}

Table 2. Assessment of the correlation between sites breeding habitats, seasons and mosquito species abundance and distribution using generalized linear model.

\begin{tabular}{cccc}
\hline & LR Chisq & Df & Pr (>Chisq) \\
\hline Mosquito Species & 22.18 & 3 & $p<0.0001$ \\
\hline Site (Urban/periurban/rural) & 939.33 & 2 & $p<0.0001$ \\
\hline Season (dry/rainy) & 108.13 & 1 & $p<0.0001$ \\
\hline Mosquito species vs. Site & 484.4 & 6 & $p<0.0001$ \\
\hline Mosquito species vs. Season & 0.81 & 3 & 0.8478 \\
\hline Site vs. Season & 180.78 & 2 & $p<0.0001$ \\
\hline Mosquito species vs. Site vs. Season & 198.02 & 6 & $p<0.0001$ \\
\hline
\end{tabular}

\subsection{Distribution of Aedes Species According to Seasons and Ecological Settings}

The abundance and distribution of Aedes mosquito species in each ecological setting was significantly different between the dry and rainy seasons $(p<0.0001)$. A high density of Aedes mosquitoes species was observed during the rainy season $(n=4706 ; 74.32 \%)$ compared to the dry season $(n=1626 ; 25.67 \%)$, especially in peri-urban $(93.83 \%)$ and urban areas $(96.81 \%)$. When assessing species richness, a high diversity of Aedes species was recorded in rural areas (four species in the dry season versus three species in the rainy season) compared to the other sites where two species were found (Figure 2). 


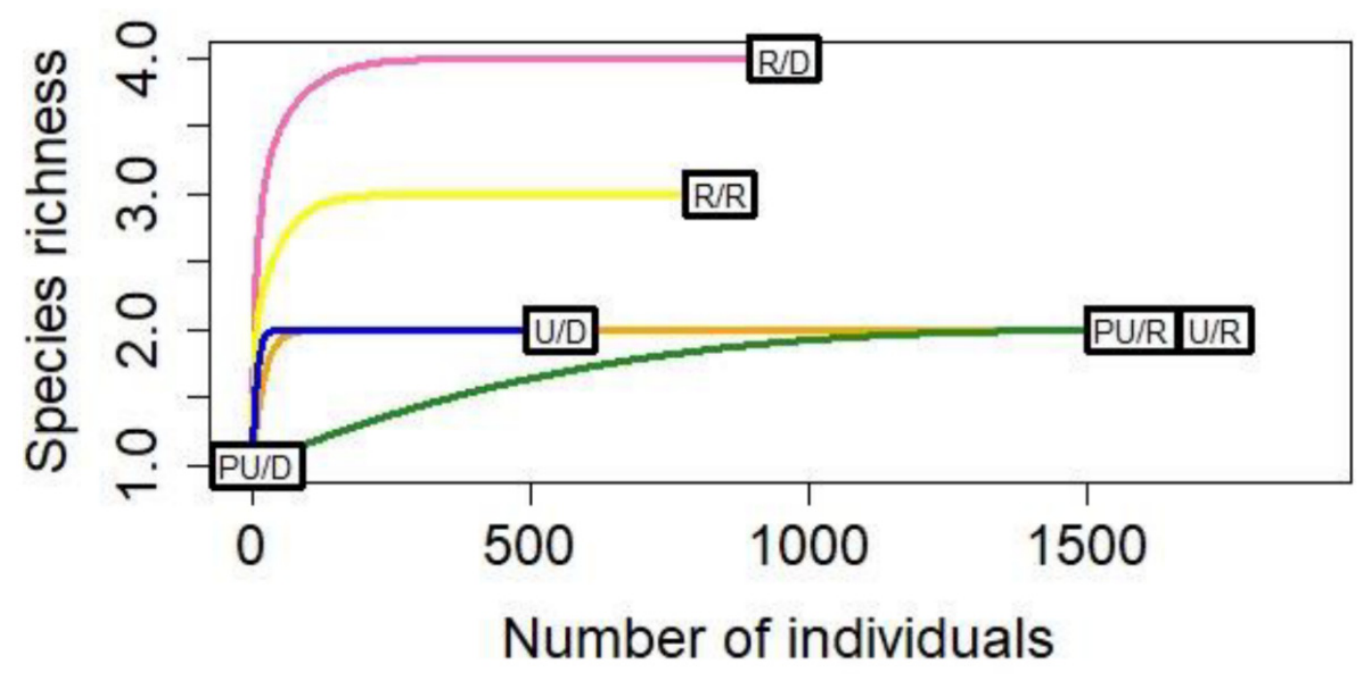

R: rural area; PU: peri-urban area; U: urban site; D: dry season ; R: rainy season

Figure 2. Rarefaction curves comparing Aedes mosquito abundance and species richness per season in each habitat type.

\subsection{Types of Aedes Breeding Habitats}

Aedes larvae were collected in a great variety of breeding sites including water containers, tires, discarded containers or plants (Figure 3). Tires (41.68\%) were the most common, followed by plastic containers (33.99\%). Out of the 403 breeding sites inspected; 86 (21.33\%) were in urban sites, $136(33.74 \%)$ in peri-urban sites and $181(44.91 \%)$ in rural sites.

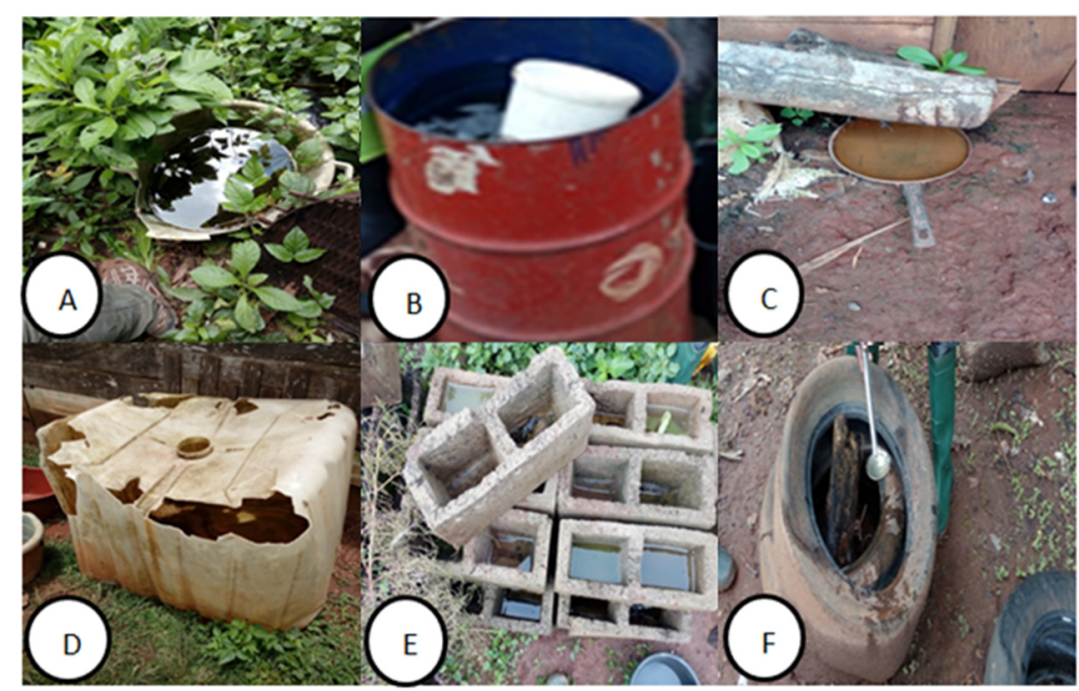

Figure 3. Aedes mosquito breeding habitats (A): plastic container; (B): tank; (C): metal; (D): plastic container; (E): cinder block; (F): tires.

Ae. albopictus larvae were mostly found in discarded tires (42.51\%) in urban and periurban areas while in rural settings, they were observed in plastic containers used for storing water $(33.30 \%$ ) (Table 2). Ae. aegypti larvae were also frequently found in plastic containers used to store water $(65.87 \%)$ at rural sites. Significant associations between the presence of plastic barrels $(p<0.0001)$, tires $(p<0.0001)$ and "others" (sprayer, sink, wheelbarrow) $(p=0.0008)$ and Ae. albopictus larvae presence were recorded $(p<<0.0001)$ (Table 3$)$. 
Table 3. Type of breeding habitats recorded with Aedes mosquito larvae in urban, peri-urban and rural settings.

\begin{tabular}{|c|c|c|c|c|c|c|c|c|}
\hline \multirow{2}{*}{$\begin{array}{l}\text { Breeding } \\
\text { Habitats }\end{array}$} & & \multicolumn{2}{|c|}{ Urban } & \multicolumn{2}{|c|}{ Peri-Urban } & \multicolumn{2}{|c|}{ Rural } & \multirow[b]{2}{*}{ Total } \\
\hline & & Obili & Mvan & Simbock & Ahala & Lendom & $\begin{array}{c}\text { Elig- } \\
\text { Essomballa }\end{array}$ & \\
\hline \multirow{3}{*}{ Tires } & $\mathbf{N}(\mathbf{a})$ & $20(9)$ & $33(7)$ & $83(42)$ & 19(5) & $5(2)$ & $8(4)$ & 168(69) \\
\hline & Ae. albopictus & 358 & 1350 & 1159 & 260 & 1 & 10 & 3138 \\
\hline & Ae. aegypti & 3 & 68 & 62 & 7 & 15 & 47 & 217 \\
\hline \multirow{4}{*}{$\begin{array}{c}\text { Plastic } \\
\text { containers }\end{array}$} & $\mathbf{N}(\mathbf{a})$ & 14(1) & $7(2)$ & 19(4) & $2(0)$ & $48(31)$ & $47(30)$ & $137(68)$ \\
\hline & Ae. albopictus & 101 & 67 & 72 & 0 & 210 & 131 & 581 \\
\hline & Ae. aegypti & 0 & 0 & 8 & 0 & 353 & 344 & 705 \\
\hline & Ae. simpsoni & 0 & 0 & 0 & 0 & 65 & 2 & 67 \\
\hline \multirow{4}{*}{$\begin{array}{l}\text { Metallic } \\
\text { containers }\end{array}$} & $\mathbf{N}(a)$ & $1(0)$ & $1(0)$ & $4(1)$ & 0 & 10(9) & 13(11) & $29(21)$ \\
\hline & Ae. albopictus & 0 & 0 & 21 & 0 & 30 & 27 & 78 \\
\hline & Ae. aegypti & 0 & 0 & 1 & 0 & 109 & 94 & 204 \\
\hline & Ae. simpsoni & 0 & 0 & 0 & 0 & 0 & 9 & 9 \\
\hline \multirow{4}{*}{$\begin{array}{l}\text { Metallic } \\
\text { tanks }\end{array}$} & $\mathbf{N}(\mathbf{a})$ & 0 & $1(0)$ & 0 & 0 & $6(6)$ & 19(8) & $26(14)$ \\
\hline & Ae. albopictus & 0 & 0 & 0 & 0 & 10 & 34 & 44 \\
\hline & Ae. aegypti & 0 & 0 & 0 & 0 & 65 & 13 & 78 \\
\hline & Ae. simpsoni & 0 & 0 & 0 & 0 & 0 & 5 & 5 \\
\hline \multirow{3}{*}{$\begin{array}{l}\text { Plastic } \\
\text { tanks }\end{array}$} & $\mathbf{N}(a)$ & 0 & $3(2)$ & 0 & $2(0)$ & $8(3)$ & $4(4)$ & 17(9) \\
\hline & Ae. albopictus & 0 & 338 & 0 & 0 & 39 & 18 & 395 \\
\hline & Ae. aegypti & 0 & 1 & 0 & 0 & 15 & 9 & 25 \\
\hline \multirow{4}{*}{$\begin{array}{l}\text { Breeze } \\
\text { block }\end{array}$} & $\mathbf{N}(\mathbf{a})$ & 0 & $3(0)$ & 0 & $2(0)$ & $2(1)$ & $3(2)$ & $10(3)$ \\
\hline & Ae. albopictus & 0 & 0 & 0 & 0 & 3 & 12 & 15 \\
\hline & Ae. aegypti & 0 & 0 & 0 & 0 & 3 & 16 & 5 \\
\hline & Ae. simpsoni & 0 & 0 & 0 & 0 & 0 & 4 & 4 \\
\hline \multirow{3}{*}{ Tree hole } & $\mathbf{N}(\mathbf{a})$ & 0 & $1(0)$ & 0 & 0 & 0 & 0 & $1(0)$ \\
\hline & Ae. albopictus & 0 & 0 & 0 & 0 & 0 & 0 & 0 \\
\hline & Ae. aegypti & 0 & 0 & 0 & 0 & 0 & 0 & 0 \\
\hline \multirow{3}{*}{$\begin{array}{l}\text { Plant } \\
\text { leaves }\end{array}$} & $\mathbf{N}(a)$ & 0 & 0 & 0 & 0 & 0 & 1(1) & 1(1) \\
\hline & Ae. albopictus & 0 & 0 & 0 & 0 & 0 & 0 & 0 \\
\hline & Ae. aegypti & 0 & 0 & 0 & 0 & 0 & 22 & 22 \\
\hline \multirow{3}{*}{ Others } & $\mathbf{N}(\mathbf{a})$ & 0 & $3(0)$ & $6(0)$ & 0 & $5(4)$ & 1(1) & 15(5) \\
\hline & Ae. albopictus & 0 & 0 & 0 & 0 & 2 & 7 & 9 \\
\hline & Ae. aegypti & 0 & 0 & 0 & 0 & 28 & 32 & 60 \\
\hline
\end{tabular}

N: total number of breeding sites inspected; (a): number of positives breeding sites; Others (sprayer, sink, wheelbarrow); plastic container refers to any container like plastic boxes, bowls, pans, without looking at their volume.

\subsection{Co-Occurence of Aedes Species in Breeding Sites}

Ae. albopictus was recorded more frequently than Ae. aegypti and was found in 154 $(70 \%)$ larval habitats, whereas Ae. aegypti larvae were recorded in $66(30 \%)$ larval habitats. Both species were found together in $71(32.27 \%)$ breeding habitats. Out of the 154 breeding habitats with Ae. albopictus larvae, 56 habitats had only Ae. albopictus and these were frequent in urban and peri-urban areas. In rural areas, Ae. albopictus was only recorded alone in seven habitats. Ae. aegypti, on the other hand, was recorded alone in 27 habitats. At several breeding sites, Ae. albopictus was found with other species. Indeed, different associations were observed with habitats containing two, three, four or five different mosquito species. The co-occurrence of different genera is also more frequent in rural areas compared to urban settings. Species belonging to different genera, including Anopheles, Culex and Eretmapodites, were detected in sympatry (co-occurrence) with Aedes larvae (Table 4). 
Table 4. Co-occurrences of Aedes species and other species in the same breeding habitats in rural, peri-urban and urban sites in Yaoundé.

\begin{tabular}{|c|c|c|c|}
\hline Species & Urban & Peri-Urban & Rural \\
\hline Ae. albopictus & $22.09 \%(19 / 86)$ & $22.05 \%(30 / 136)$ & $3.86 \%(7 / 181)$ \\
\hline Ae. aegypti & 0 & 0 & $14.91 \%(27 / 181)$ \\
\hline Ae. albopictus + Ae. aegypti & $3.48 \%(3 / 86)$ & $10.29 \%(14 / 136)$ & $12.15 \%(22 / 181)$ \\
\hline Ae. albopictus + Ae. simpsoni & 0 & 0 & $0.55 \%(1 / 181)$ \\
\hline Ae. albopictus + Ae. aegypti + Ae. simpsoni & 0 & 0 & $4.41 \%(8 / 181)$ \\
\hline Ae. albopictus + Ae. aegypti + Ae. simpsoni $+C x$. culiciomayia group & 0 & 0 & $1.10 \%(2 / 181)$ \\
\hline Ae. albopictus + Ae. aegypti + Ae. simpsoni $+C x$. Duttoni & 0 & 0 & $0.55 \%(1 / 181)$ \\
\hline $\begin{array}{c}\text { Ae. albopictus }+ \text { Ae. aegypti }+ \text { Ae. simpsoni }+C x . \text { Culiciomayia group }+C x . \\
\text { antennatus }\end{array}$ & 0 & 0 & $0.55 \%(1 / 181)$ \\
\hline Ae. albopictus $+C x$. quinquefasciatus & $2.94 \%(4 / 136)$ & $0.73 \%(1 / 136)$ & $0.55 \%(1 / 181)$ \\
\hline Ae. albopictus $+C x$. duttoni & $2.20 \%(3 / 136)$ & $0.73 \%(1 / 136)$ & $0.55 \%(1 / 181)$ \\
\hline Ae. albopictus + Lutzia tigripes & 0 & $0.73 \%(1 / 136)$ & 0 \\
\hline Ae. albopictus $+C x$. Culiciomayia group & 0 & $0.73 \%(1 / 136)$ & 0 \\
\hline Ae. albopictus $+C x$. Culiciomayia group $+C x$. Duttoni & 0 & $0.73 \%(1 / 136)$ & 0 \\
\hline Ae. albopictus $+C x$. Culiciomayia group $+C x$. quinquefasciatus & 0 & 0 & $0.55 \%(1 / 181)$ \\
\hline Ae. albopictus $+C x$. quinquefasciatus + Lutzia tigripes & $0.73 \%(1 / 136)$ & 0 & 0 \\
\hline Ae. aegypti + Cx. Culiciomayia group & 0 & 0 & $1.65 \%(3 / 181)$ \\
\hline Ae. aegypti $+C x$. Culiciomayia group $+C x$. quinquefasciatus + Lutzia tigripes & 0 & 0 & $0.55 \%(1 / 181)$ \\
\hline Ae. aegypti $+C x$. duttoni + Lutzia tigripes & 0 & 0 & $1.10 \%(2 / 181)$ \\
\hline Ae.aegypti + Ae. simpsoni + Lutzia tigripes & 0 & 0 & $0.55 \%(1 / 181)$ \\
\hline Ae.aegypti $+C x$. quinquefasciatus + Eretmapodites $s p$ & 0 & 0 & $0.55 \%(1 / 181)$ \\
\hline Ae. albopictus + Ae. aegypti $+C x$. quinquefasciatus & $0.73 \%(1 / 136)$ & $(4 / 136)$ & $1.65 \%(3 / 181)$ \\
\hline Ae. albopictus + Ae. aegypti $+C x$. duttoni & 0 & $0.73 \%(1 / 136)$ & $2.76 \%(5 / 181)$ \\
\hline Ae. albopictus + Ae. aegypti $+C x$. antennatus & 0 & 0 & $0.55 \%(1 / 181)$ \\
\hline Ae. albopictus + Ae. aegypti + Lutzia tigripes & 0 & 0 & $0.55 \%(1 / 181)$ \\
\hline Ae. albopictus + Ae. aegypti $+C x$. Culiciomayia group & 0 & $0.73 \%(1 / 136)$ & $1.10 \%(2 / 181)$ \\
\hline Ae. albopictus $+A e$. aegypti $+C x$. duttoni $+C x$. quinquefasciatus & 0 & $0.73 \%(1 / 136)$ & $1.65 \%(3 / 181)$ \\
\hline Ae. albopictus + Ae. aegypti $+C x$. Culiciomayia group $+C x$. duttoni & 0 & 0 & $0.55 \%(1 / 181)$ \\
\hline Ae. albopictus + Ae. aegypti $+C x$. Culiciomayia group $+C x$. antennatus & 0 & 0 & $0.55 \%(1 / 181)$ \\
\hline Ae. albopictus + Ae. aegypti $+C x$. duttoni + Lutzia tigripes & 0 & 0 & $0.55 \%(1 / 181)$ \\
\hline Ae. aegypti + Ae. albopictus + Eretmapodites & 0 & 0 & $1.10 \%(2 / 181)$ \\
\hline $\begin{array}{c}\text { Ae. albopictus }+ \text { Ae. aegypti }+C x . \text { Culiciomayia group }+C x . \text { quinquefasciatus }+ \\
\text { Lutzia tigripes }+ \text { An. funestus }\end{array}$ & 0 & 0 & $0.55 \%(1 / 181)$ \\
\hline $\begin{array}{c}\text { Ae. albopictus }+ \text { Ae. aegypti }+ \text { Ae. simpsoni }+C x . \text { Culiciomayia group }+C x . \\
\text { quinquefasciatus }\end{array}$ & 0 & 0 & $0.55 \%(1 / 181)$ \\
\hline
\end{tabular}

\subsection{Distance of the Breeding Sites to the Nearest House}

Most Aedes mosquitoes' breeding places were found close to human habitations. Over $50 \%$ of breeding sites were situated less than $10 \mathrm{~m}$ from houses at all sites. Less than $20 \%$ of the breeding sites in urban, peri-urban and rural areas were situated above $50 \mathrm{~m}$. In rural areas, up to $70 \%$ of breeding places were situated less than $10 \mathrm{~m}$ from houses (Figure 4 ).

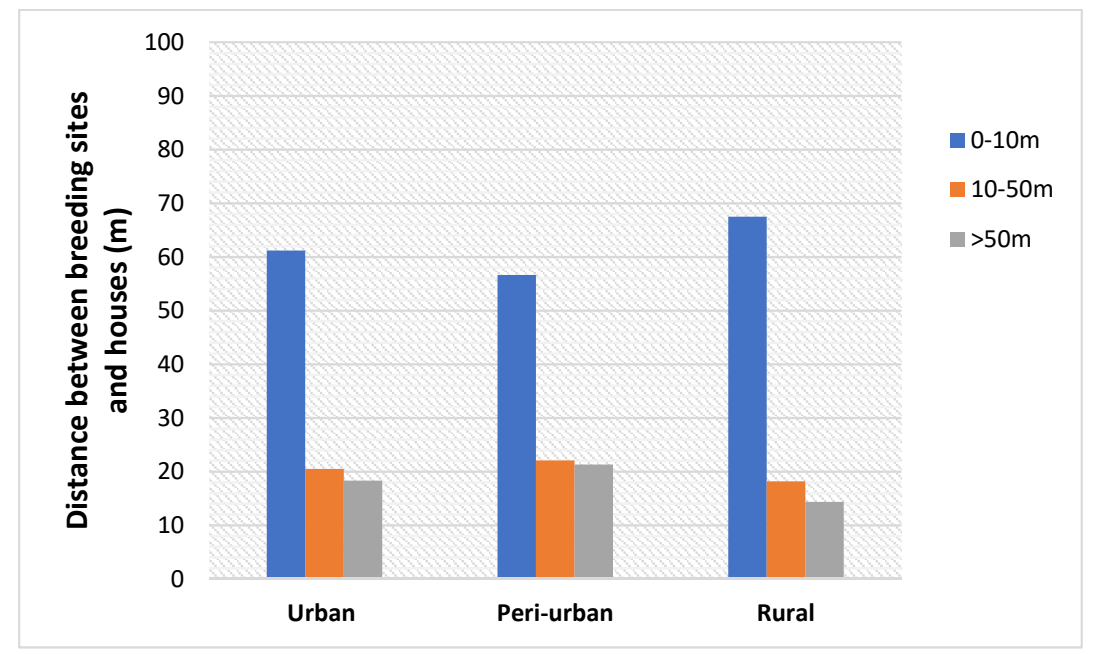

Figure 4. Distance between breeding habitats and houses. 


\subsection{Estimation of Entomological Indices (Stegomyia Indices)}

An estimation of Stegomyia indices was performed to assess the risk of arbovirus transmission in different ecological settings. High Breteau (49.38\%) and Containers (62.66\%) indexes were registered in urban sites (Table 5). In peri-urban settings, the container index $(46.29 \%)$ was the highest index, while the house index $(44.91 \%)$ was the highest in rural settings.

Table 5. Entomological Stegomyia indices in urban, peri-urban and rural settings.

\begin{tabular}{cccc}
\hline \multicolumn{4}{c}{ Stegomyia Indices } \\
\hline Sites & Breteau Index (95\% CI) & Container Index (95\% CI) & House Index (95\% CI) \\
\hline Urban & $49.38 \%(41.07-57.69)$ & $70.02 \%(67.64-72.41)$ & $40.72 \%(40.38-41.07)$ \\
Peri-urban & $40.27 \%(25-55.55)$ & $42.71 \%(39.13-46.29)$ & $41.94 \%(25-58.88)$ \\
Rural & $42.31 \%(35.44-49.18)$ & $34.62 \%(29.78-39.47)$ & $44.91 \%(44.26-45.56)$ \\
\hline
\end{tabular}

95\% CI: $95 \%$ confidence interval.

\section{Discussion}

This study indicated a permanent presence of Aedes mosquito species in Yaoundé and its neighbourhood. Aedes species observed included Ae. aegypti and Ae. albopictus, which are largely distributed across the country [37]. Ae. simpsoni was also registered in the collections conducted in rural areas. Previous studies reported the presence of this species in rural settings of Cameroon [31,38-40]. Some Aedes species were recorded but could not be identified to the species level and were termed Aedes spp. Aedes species were observed in association with culicine species such as Culex quinquefasciatus, Cx. duttoni, $C x$. antennatus, Lutzia tigripes, $C x$. Culiciomayia group, Eretmapodites sp. Aedes species were recorded during both the rainy and dry seasons, yet a slight increase in densities was observed during the rainy season in all three sites, supporting a dependence on seasonal conditions. Aedes species were observed breeding in different types of habitats including plastic or metallic containers, discarded tires, cans, tree holes and in leaves. Although Ae. aegypti and Ae. albopictus were found to prefer human made habitats, different preferences were observed for the two species. Ae. aegypti was found to be abundant in water storage containers (plastics and metal), especially water jars, whereas Ae. albopictus was highly prevalent in discarded tires, empty cans and containers. These findings were in accordance with previous studies in Cameroon [41,42] and elsewhere in central Africa [43-45]. Used vehicle tires have been reported as the main larval habitats and presumably one of the most productive for Ae. Albopictus [41,42]. Aedes albopictus was also reported to produce eggs resistant to desiccation; these specific adaptation characteristics could have promoted the distribution of the species across the world [46]. As a result of an overlapping geographical distribution and shared microhabitats between Ae. aegypti and Ae. albopictus, it has been proposed that competition during larval development is shaping the distribution of both species. Recent studies suggested that the invasion of most parts of the world by Ae. albopictus has induced a decline in the abundance of Ae. aegypti and could even lead to its disappearance when both of them share the same larval breeding place. A competitive displacement of Ae. aegypti by Ae. albopictus has been documented in previous studies [47]. In the Americas, in both Brazil and the USA, it was reported that competition during larval development contributed to the displacement of Ae. aegypti by Ae. albopictus in various places [48-50]. It is possible that interspecific interactions between adult mosquitoes, such as interspecific mating or satyrization on female Ae. aegypti as they mate freely with male Ae. albopictus in addition to males of their own species [51,52], could be shaping the distribution of the two species. Studies from the University of Florida indicated that female Ae. aegypti have evolved resistance to cross-mating [52,53]. It is so far not known whether interspecific mating is shaping the distribution of Ae. aegypti and Ae. albopictus in Cameroon and this deserves further investigation and regular surveillance of vector population dynamics. 
In Yaoundé, Ae. aegypti was the predominant species in the urban environment before the introduction of Ae. albopictus. Since Ae. albopictus' introduction in the late 1990s [17], this species has now become the predominant species in both urban and peri-urban areas; whereas Ae. aegypti is now mostly found in rural settings. Our findings are in accordance with previous studies in the city of Yaoundé and in Cameroon [37,41,54,55]. However, although in Brazil, Ae. albopictus was first detected in 1986 and has now invaded almost all Brazilian states [56,57], the distribution pattern of Ae. albopictus was found to be different from the situation in Cameroon with Aedes aegypti predominating in urban areas, whereas Ae. albopictus is most prevalent in suburban and rural vegetated areas [58,59]. Nevertheless, a shift in Ae. aegypti distribution as a consequence of the invasion by Ae. albopictus has been reported in many places including Brazil, Florida [58,60,61], Puerto Rico [62] and the Mayotte island [63].

In the present study, out of 189 habitats found with larvae, Ae. albopictus was observed alone in $29.62 \%(56 / 189)$ and with $A$ e. aegypti in $61.37 \%(116 / 189)$ of the total habitats. These findings show the high frequency of the co-occurrence of the two species in nature. The ratio of Ae. aegypti/Ae. albopictus was 2.18:1 in rural settings, whereas this same ratio was approximately 1:25 in urban and peri-urban sites. These figures support the competitive superiority of Ae. albopictus to Ae. aegypti in urban and peri-urban sites. Similar observations in field and laboratory experiments have been made by previous studies, particularly in resource-limited conditions $[49,64]$. Yet the coexistence of Ae. aegypti and Ae. albopictus could be highly context-dependent and may depend on different factors including the specificity of aquatic resources or diet. A diet based on rapidly decaying resources, such as yeast, animal detritus or dead insects, was found to reduce competition between $A e$. albopictus and Ae. aegypti and allowed their coexistence, while a diet based on deciduous or coniferous leaves was found to favour Ae. albopictus $[49,64-66]$. Seasonal variations alongside eggs desiccation was also found to affect the distribution and coexistence of both species [51]. Indeed, despite the fact that both species' eggs could resist different environmental conditions, the drying of containers was found to be much more detrimental to Ae. albopictus eggs than to Ae. aegypti eggs in the Americas [51,67]. In studies conducted in Rio de Janeiro, Brazil, it appears that the end of the dry season was more favourable for Ae. aegypti than for Ae. albopictus immatures, which were found to be less abundant during this period [68]. It is not clear at this level whether a similar distribution pattern applies for both species in Cameroon.

Although at a global level, Ae. albopictus seems to be selecting for artificial containers when introduced to urban areas, it appeared that Ae. albopictus' preferred breeding habitats in rural sites were tree holes and leaf axils instead of artificial containers, which support a preference for natural sites in rural environments. Studies in Brazil and the western hemisphere also suggest $A e$. albopictus has a high preference for natural containers in forested areas [68]. Competition between Ae. aegypti and Ae. albopictus could also negatively affect adult size, development rate, longevity and vectorial capacity [68]. Continuous surveillance should be carried out in Yaoundé to follow the evolution of these mosquito species, which are efficient vectors of arboviruses [25-27].

A low dispersion rate of Aedes species was recorded, with over $60 \%$ of the breeding places found between $0-10 \mathrm{~m}$ from human habitations. This could be attributed to the dependence of Ae. albopictus and Ae. aegypti upon humans as a source of blood meal. Indeed, Aedes species frequently colonize breeding and resting-habitats close to human dwellings. The high Stegomyia indexes observed in this study could result from the close proximity of both species to human dwellings as recently reported in the city of Yaoundé [55].

In regard to Aedes mosquito distribution in Yaoundé, the implementation of control strategies, such as the promotion of hygiene and the elimination of empty cans and containers around houses, has become important. The elimination of spare tires of vehicles or their collection and storage at specific sites in the city should also be envisaged to reduce Aedes albopictus' preferential breeding places. In rural settings, people should cover containers 
used for water storage to stop mosquito oviposition in these containers. Larval source management could also be implemented alongside campaigns to control Aedes populations.

\section{Conclusions}

Aedes mosquito species are largely distributed in different habitats of Yaoundé where they have colonized a great variety of water holding containers found around human dwellings. With the increasing number of arbovirus cases registered in Yaoundé, it is becoming urgent to implement control measures, such as larval source management, against these vectors to prevent the spread of arboviral diseases in Cameroon.

Author Contributions: B.D.-T. and C.A.-N. conceptualized the study; B.D.-T., M.S.N.-N., I.M. and E.N. performed data curation; B.D.-T., M.S.N.-N., I.M., E.N., A.T., E.K., R.B. and M.P.A.M. performed the investigation and methodology; B.D.-T., M.S.N.-N., I.M., E.N., A.T., E.K., R.B., M.P.A.M., P.A.-A., T.T., C.W., C.A.-N. visualized the study; E.N., R.B., M.P.A.M. were responsible for the software management; B.D.-T., M.S.N.-N., E.N., A.T., E.K., R.B. and M.P.A.M. wrote the original draft; T.T., E.N., P.A.-A., C.W. and C.A.-N. supervised and provided resources for the study; T.T., E.N., P.A.-A., C.W. and C.A.-N. were responsible for the study' administration and validation; T.T., E.N., P.A.-A., C.W. and C.A.-N. wrote, reviewed and edited the study. All authors have read and agreed to the published version of the manuscript.

Funding: This study received financial support from the Welcome Trust Senior Fellowship in Public Health and Tropical Medicine [202687/Z/16/Z] awarded to CAN and from MTN-KFW program awarded to N.-N.S.M.

Institutional Review Board Statement: The study was conducted according to the guidelines of the Declaration of Helsinki, and approved by the Cameroon national Ethics Committee for research on human health, Ethical Clearance N0 2018/06/1039/CE/CNERSH/SP REF N0 D30- 172/LMINSANTE/SG/DROS/TMC of the 4 April 2017.

Data Availability Statement: All the data from the study is available in the manuscript.

Acknowledgments: We would like to thank NGANGUE Nasser for his help during field work activities.

Conflicts of Interest: The authors declare that they have no competing interests.

\section{References}

1. Bhatt, S.; Gething, P.W.; Brady, O.J.; Messina, J.P.; Farlow, A.W.; Moyes, C.L.; Drake, J.M.; Brownstein, J.S.; Hoen, A.G.; Sankoh, O.; et al. The Global Distribution and Burden of Dengue. Nature 2013, 496, 504-507. [CrossRef]

2. Weaver, S.C.; Reisen, W.K. Present and Future Arboviral Threats. Antiviral Res. 2010, 85, 328-345. [CrossRef]

3. Ayolabi, C.I.; Olusola, B.A.; Ibemgbo, S.A.; Okonkwo, G.O. Detection of Dengue Viruses among Febrile Patients in Lagos, Nigeria and Phylogenetics of Circulating Dengue Serotypes in Africa. Infect. Genet. Evol. J. Mol. Epidemiol. Evol. Genet. Infect. Dis. 2019, 75, 103947. [CrossRef] [PubMed]

4. Lutomiah, J.; Barrera, R.; Makio, A.; Mutisya, J.; Koka, H.; Owaka, S.; Koskei, E.; Nyunja, A.; Eyase, F.; Coldren, R.; et al. Dengue Outbreak in Mombasa City, Kenya, 2013-2014: Entomologic Investigations. PLoS Negl. Trop. Dis. 2016, 10, e0004981. [CrossRef] [PubMed]

5. Otu, A.; Udoh, U.; Ita, O.; Hicks, J.; Ukpeh, I.; Walley, J. Prevalence of Zika and Malaria in Patients with Fever in Secondary Healthcare Facilities in South-Eastern Nigeria. Trop Doct. 2020, 50, 22-30. [CrossRef]

6. Proesmans, S.; Katshongo, F.; Milambu, J.; Fungula, B.; Mavoko, H.M.; Ahuka-Mundeke, S.; da Luz, R.I.; Esbroeck, M.V.; Ariën, K.K.; Cnops, L.; et al. Dengue and Chikungunya among Outpatients with Acute Undifferentiated Fever in Kinshasa, Democratic Republic of Congo: A Cross-Sectional Study. PLoS Negl. Trop. Dis. 2019, 13, e0007047. [CrossRef] [PubMed]

7. Kading, R.C.; Brault, A.C.; Beckham, J.D. Global Perspectives on Arbovirus Outbreaks: A 2020 Snapshot. Trop. Med. Infect. Dis. 2020, 5, 142. [CrossRef] [PubMed]

8. Arias-Goeta, C.; Moutailler, S.; Mousson, L.; Zouache, K.; Thiberge, J.-M.; Caro, V.; Rougeon, F.; Failloux, A.-B. Chikungunya Virus Adaptation to a Mosquito Vector Correlates with Only Few Point Mutations in the Viral Envelope Glycoprotein. Infect. Genet. Evol. 2014, 24, 116-126. [CrossRef]

9. Novella, I.S.; Presloid, J.B.; Smith, S.D.; Wilke, C.O. Specific and Nonspecific Host Adaptation during Arboviral Experimental Evolution. Microb. Physiol. 2011, 21, 71-81. [CrossRef]

10. Ramasamy, R. Adaptation of Freshwater Mosquito Vectors to Salinity Increases Arboviral Disease Transmission Risk in the Context of Anthropogenic Environmental Changes. In Global Virology I-Identifying and Investigating Viral Diseases; Shapshak, P., Sinnott, J.T., Somboonwit, C., Kuhn, J.H., Eds.; Springer: New York, NY, USA, 2015; pp. 45-54, ISBN 978-1-4939-2410-3. 
11. Gould, E.; Pettersson, J.; Higgs, S.; Charrel, R.; de Lamballerie, X. Emerging Arboviruses: Why Today? One Health 2017, 4, 1-13. [CrossRef]

12. McMichael, A.J.; Woodruff, R.E.; Hales, S. Climate Change and Human Health: Present and Future Risks. Lancet 2006, 367, 859-869. [CrossRef]

13. Wilder-Smith, A.; Ooi, E.-E.; Horstick, O.; Wills, B. Dengue. Lancet 2019, 393, 350-363. [CrossRef]

14. WHO. WHO Global Vectors Control Response, 2017-2030; WHO: Geneva, Switzerland, 2017.

15. Boyer, S.; Calvez, E.; Chouin-Carneiro, T.; Diallo, D.; Failloux, A.-B. An Overview of Mosquito Vectors of Zika Virus. Microbes Infect. 2018, 20, 646-660. [CrossRef] [PubMed]

16. Diallo, D.; Sall, A.A.; Diagne, C.T.; Faye, O.; Faye, O.; Ba, Y.; Hanley, K.A.; Buenemann, M.; Weaver, S.C.; Diallo, M. Zika Virus Emergence in Mosquitoes in Southeastern Senegal, 2011. PLoS ONE 2014, 9, e109442. [CrossRef]

17. Fontenille, D.; Toto, J.C. Aedes (Stegomyia) Albopictus (Skuse), a Potential New Dengue Vector in Southern Cameroon. Emerg. Infect. Dis. 2001, 7, 1066. [CrossRef] [PubMed]

18. Rageau, J.; Adam, J.-P. Culicinæ du cameroun. Ann. Parasitol. Hum. Comparée 1952, 27, 610-635. [CrossRef]

19. Demanou, M.; Pouillot, R.; Grandadam, M.; Boisier, P.; Kamgang, B.; Hervé, J.P.; Rogier, C.; Rousset, D.; Paupy, C. Evidence of Dengue Virus Transmission and Factors Associated with the Presence of Anti-Dengue Virus Antibodies in Humans in Three Major Towns in Cameroon. PLoS Negl. Trop. Dis. 2014, 8, e2950. [CrossRef] [PubMed]

20. Gake, B.; Vernet, M.A.; Leparc-Goffart, I.; Drexler, J.F.; Gould, E.A.; Gallian, P.; de Lamballerie, X.; Gake, B.; Vernet, M.A.; Leparc-Goffart, I.; et al. Low Seroprevalence of Zika Virus in Cameroonian Blood Donors. Braz. J. Infect. Dis. 2017, 21, 481-483. [CrossRef] [PubMed]

21. Nemg Simo, F.B.; Sado Yousseu, F.B.; Evouna Mbarga, A.; Bigna, J.J.; Melong, A.; Ntoude, A.; Kamgang, B.; Bouyne, R.; Moundipa Fewou, P.; Demanou, M. Investigation of an Outbreak of Dengue Virus Serotype 1 in a Rural Area of Kribi, South Cameroon: A Cross-Sectional Study. Intervirology 2018, 61, 265-271. [CrossRef]

22. Tchuandom, S.B.; Tchouangueu, T.F.; Antonio-Nkondjio, C.; Lissom, A.; Djang, J.O.N.; Atabonkeng, E.P.; Kechia, A.; Nchinda, G.; Kuiate, J.-R. Seroprevalence of Dengue Virus among Children Presenting with Febrile Illness in Some Public Health Facilities in Cameroon. Pan Afr. Med. J. 2018, 31. [CrossRef]

23. Tchuandom, S.B.; Tchadji, J.C.; Tchouangueu, T.F.; Biloa, M.Z.; Atabonkeng, E.P.; Fumba, M.I.M.; Massom, E.S.; Nchinda, G.; Kuiate, J.-R. A Cross-Sectional Study of Acute Dengue Infection in Paediatric Clinics in Cameroon. BMC Public Health 2019, 19, 1-7. [CrossRef]

24. Yousseu, F.B.S.; Nemg, F.B.S.; Ngouanet, S.A.; Mekanda, F.M.O.; Demanou, M. Detection and Serotyping of Dengue Viruses in Febrile Patients Consulting at the New-Bell District Hospital in Douala, Cameroon. PLoS ONE 2018, 13, e0204143. [CrossRef]

25. Kamgang, B.; Vazeille, M.; Tedjou, A.; Yougang, A.P.; Wilson-Bahun, T.A.; Mousson, L.; Wondji, C.S.; Failloux, A.-B. Different Populations of Aedes Aegypti and Aedes Albopictus (Diptera: Culicidae) from Central Africa Are Susceptible to Zika Virus Infection. PLoS Negl. Trop. Dis. 2020, 14, e0008163. [CrossRef]

26. Kamgang, B.; Vazeille, M.; Tedjou, A.N.; Wilson-Bahun, T.A.; Yougang, A.P.; Mousson, L.; Wondji, C.S.; Failloux, A.-B. Risk of Dengue in Central Africa: Vector Competence Studies with Aedes Aegypti and Aedes Albopictus (Diptera: Culicidae) Populations and Dengue 2 Virus. PLoS Negl. Trop. Dis. 2019, 13. [CrossRef]

27. Kamgang, B.; Vazeille, M.; Yougang, A.P.; Tedjou, A.N.; Wilson-Bahun, T.A.; Mousson, L.; Wondji, C.S.; Failloux, A.-B. Potential of Aedes Albopictus and Aedes Aegypti (Diptera: Culicidae) to Transmit Yellow Fever Virus in Urban Areas in Central Africa. Emerg. Microbes Infect. 2019, 8, 1636-1641. [CrossRef]

28. Roslan, M.; Ngui, R.; Vythilingam, I.; Wan Sulaiman, W. Evaluation of Sticky Traps for Adult Aedes Mosquitoes in Malaysia: A Potential Monitoring and Surveillance Tool for the Efficacy of Control Strategies. J. Vector Ecol. 2017, 42, 298-307. [CrossRef] [PubMed]

29. Schoener, E.; Zittra, C.; Weiss, S.; Walder, G.; Barogh, B.S.; Weiler, S.; Fuehrer, H.-P. Monitoring of Alien Mosquitoes of the Genus Aedes (Diptera: Culicidae) in Austria. Parasitol. Res. 2019, 118, 1633-1638. [CrossRef] [PubMed]

30. Li, Y.; Kamara, F.; Zhou, G.; Puthiyakunnon, S.; Li, C.; Liu, Y.; Zhou, Y.; Yao, L.; Yan, G.; Chen, X.-G. Urbanization Increases Aedes Albopictus Larval Habitats and Accelerates Mosquito Development and Survivorship. PLoS Negl. Trop. Dis. 2014, 8, e3301. [CrossRef] [PubMed]

31. Mayi, M.P.A.; Bamou, R.; Djiappi-Tchamen, B.; Fontaine, A.; Jeffries, C.L.; Walker, T.; Antonio-Nkondjio, C.; Cornel, A.J.; Tchuinkam, T. Habitat and Seasonality Affect Mosquito Community Composition in the West Region of Cameroon. Insects 2020, 11, 312. [CrossRef]

32. PAHO. Dengue and Dengue Hemorrhagic Fever in the Americas: Guidelines for Prevention and Control; PAHO: Washington, DC, USA, 1994.

33. Cameroun Fiche Pays PopulationData.Net 2018. Available online: https://www.populationdata.net/pays/cameroun/ (accessed on 16 May 2021).

34. Low, G.K.-K.; Ogston, S.A.; Yong, M.-H.; Gan, S.-C.; Chee, H.-Y. Global Dengue Death before and after the New World Health Organization 2009 Case Classification: A Systematic Review and Meta-Regression Analysis. Acta Trop. 2018, 182, 237-245. [CrossRef]

35. Sanchez, L.; Vanlerberghe, V.; Alfonso, L.; del Carmen Marquetti, M.; Guzman, M.G.; Bisset, J.; van der Stuyft, P. Aedes Aegypti Larval Indices and Risk for Dengue Epidemics. Emerg. Infect. Dis. 2006, 12, 800-806. [CrossRef] 
36. WHO. WHO Technical Guide for a System of Yellow Fever Surveillance; WHO: Geneva, Switzerland, 1971.

37. Tedjou, A.N.; Kamgang, B.; Yougang, A.P.; Njiokou, F.; Wondji, C.S. Update on the Geographical Distribution and Prevalence of Aedes Aegypti and Aedes Albopictus (Diptera: Culicidae), Two Major Arbovirus Vectors in Cameroon. PLoS Negl. Trop. Dis. 2019, 13, e0007137. [CrossRef] [PubMed]

38. Brottes, H.; Rickenbach, A.; Brès, P.; Williams, M.C.; Salaun, J.J.; Ferrara, L. Le virus Okola (YM 50/64) nouveau prototype d'arbovirus isolé au Cameroun à partir de moustiques. Ann. Inst. Pasteur 1969, 116, 543-551.

39. Rickenbach, A.; Gonidec, L. L'incidence Des Arbovirus Isolés Des Moustiques Dans Une Région Forestière Du Sur Cameroun, La Région de Yaoundé. Bulletin de la Société de Pathologie Exotique 1976, 69, 372-381.

40. Salaun, J.J.; Rickenbach, A.; Brès, P.; Brottes, H.; Germain, M.; Eouzan, J.-P.; Ferrara, L. Le virus Nkolbisson (YM 31/65) nouveau prototype d'arbovirus isolé au Cameroun. Ann. Inst. Pasteur 1969, 116, 254-260.

41. Kamgang, B.; Yougang, A.P.; Tchoupo, M.; Riveron, J.M.; Wondji, C. Temporal Distribution and Insecticide Resistance Profile of Two Major Arbovirus Vectors Aedes Aegypti and Aedes Albopictus in Yaoundé, the Capital City of Cameroon. Parasit. Vectors 2017, 10, 469. [CrossRef]

42. Hondt, O.E.N.; Ntonga, P.A.; Hiol, J.V.N.; Edou, D.N.; Tonga, C.; Foko, D.; Kekeunou, S. Adaptation Compétitive d'Aedes Albopictus Skuse, 1894 En Présence d'Aedes Aegypti Linné, 1862 Dans Quelques Gîtes Larvaires Temporaires de La Ville de Douala (Cameroun) Dans Un Contexte de Résistance Aux Pyréthrinoïdes. Bulletin de la Société de pathologie exotique 2020, 113, 79-87. [CrossRef]

43. Coffinet, T.; Mourou, J.R.; Pradines, B.; Toto, J.C.; Jarjaval, F.; Amalvict, R.; Kombila, M.; Carnevale, P.; Pagès, F. First Record of Aedes Albopictus InGabon. J. Am. Mosq. Control Assoc. 2007, 23, 471-472. [CrossRef]

44. Wat'senga Tezzo, F.; Fasine, S.; Manzambi Zola, E.; del Marquetti, M.C.; Binene Mbuka, G.; Ilombe, G.; Mundeke Takasongo, R.; Smitz, N.; Bisset, J.A.; Van Bortel, W.; et al. High Aedes Spp. Larval Indices in Kinshasa, Democratic Republic of Congo. Parasit. Vectors 2021, 14, 92. [CrossRef]

45. Wilson-Bahun, T.A.; Kamgang, B.; Lenga, A.; Wondji, C.S. Larval Ecology and Infestation Indices of Two Major Arbovirus Vectors, Aedes Aegypti and Aedes Albopictus (Diptera: Culicidae), in Brazzaville, the Capital City of the Republic of the Congo. Parasit. Vectors 2020, 13, 492. [CrossRef]

46. Chareonviriyaphap, T.; Bangs, M.J.; Suwonkerd, W.; Kongmee, M.; Corbel, V.; Ngoen-Klan, R. Review of Insecticide Resistance and Behavioral Avoidance of Vectors of Human Diseases in Thailand. Parasit. Vectors 2013, 6, 280. [CrossRef]

47. Lounibos, L.P.; Suárez, S.; Menéndez, Z.; Nishimura, N.; Escher, R.L.; O'Connell, S.M.; Rey, J.R. Does Temperature Affect the Outcome of Larval Competition between Aedes Aegypti and Aedes Albopictus? J. Vector Ecol. J. Soc. Vector Ecol. 2002, $27,86-95$.

48. Braks, M.A.H.; Honório, N.A.; Lounibos, L.P.; Lourenço-De-Oliveira, R.; Juliano, S.A. Interspecific Competition Between Two Invasive Species of Container Mosquitoes, Aedes Aegypti and Aedes Albopictus (Diptera: Culicidae), in Brazil. Ann. Entomol. Soc. Am. 2004, 97, 130-139. [CrossRef]

49. Daugherty, M.P.; Alto, B.W.; Juliano, S.A. Invertebrate Carcasses as a Resource for Competing Aedes Albopictus and Aedes Aegypti (Diptera: Culicidae). J. Med. Entomol. 2000, 37, 364-372. [CrossRef] [PubMed]

50. Juliano, S.A. Species Introduction and Replacement among Mosquitoes: Interspecific Resource Competition or Apparent Competition? Ecology 1998, 79, 255-268. [CrossRef]

51. Juliano, S.A.; O'Meara, G.F.; Morrill, J.R.; Cutwa, M.M. Desiccation and Thermal Tolerance of Eggs and the Coexistence of Competing Mosquitoes. Oecologia 2002, 130, 458-469. [CrossRef]

52. Juliano, S.A.; Lounibos, L.P.; O'Meara, G.F. A Field Test for Competitive Effects of Aedes Albopictus on A. Aegypti in South Florida: Differences between Sites of Coexistence and Exclusion? Oecologia 2004, 139, 583-593. [CrossRef]

53. Hornby, J.A.; Moore, D.E.; Miller, T.W. Aedes Albopictus Distribution, Abundance, and Colonization in Lee County, Florida, and Its Effect on Aedes Aegypti. J. Am. Mosq. Control Assoc. 1994, 10, 397-402.

54. Simard, F.; Nchoutpouen, E.; Toto, J.C.; Fontenille, D. Geographic Distribution and Breeding Site Preference of Aedes Albopictus and Aedes Aegypti (Diptera: Culicidae) in Cameroon, Central Africa. J. Med. Entomol. 2005, 42, 726-731. [CrossRef]

55. Tedjou, A.N.; Kamgang, B.; Yougang, A.P.; Wilson-Bahun, T.A.; Njiokou, F.; Wondji, C.S. Patterns of Ecological Adaptation of Aedes Aegypti and Aedes Albopictus and Stegomyia Indices Highlight the Potential Risk of Arbovirus Transmission in Yaoundé, the Capital City of Cameroon. Pathogens 2020, 9, 491. [CrossRef]

56. Carvalho, R.G.; Lourenço-de-Oliveira, R.; Braga, I.A. Updating the Geographical Distribution and Frequency of Aedes Albopictus in Brazil with Remarks Regarding Its Range in the Americas. Mem. Inst. Oswaldo Cruz 2014, 109, 787-796. [CrossRef]

57. Pancetti, F.G.M.; Honório, N.A.; Urbinatti, P.R.; Lima-Camara, T.N. Twenty-Eight Years of Aedes Albopictus in Brazil: A Rationale to Maintain Active Entomological and Epidemiological Surveillance. Rev. Soc. Bras. Med. Trop. 2015, 48, 87-89. [CrossRef] [PubMed]

58. Braks, M.A.H.; Honório, N.A.; Lourenço-De-Oliveira, R.; Juliano, S.A.; Lounibos, L.P. Convergent Habitat Segregation of Aedes Aegypti and Aedes Albopictus (Diptera: Culicidae) in Southeastern Brazil and Florida. J. Med. Entomol. 2003, 40, 785-794. [CrossRef]

59. Honório, N.A.; Castro, M.G.; de Barros, F.S.M.; Magalhães, M.D.A.F.M.; Sabroza, P.C. The Spatial Distribution of Aedes Aegypti and Aedes Albopictus in a Transition Zone, Rio de Janeiro, Brazil. Cad. Saúde Pública Rio de Janeiro 2009, 25, 1203-1214. [CrossRef] [PubMed] 
60. de Lima-Camara, T.N.; Honório, N.A.; Lourenço-de-Oliveira, R. Frequency and spatial distribution of Aedes aegypti and Aedes albopictus (Diptera, Culicidae) in Rio de Janeiro, Brazil. Cad. Saúde Pública 2006, 22, 2079-2084. [CrossRef]

61. O'Meara, G.; Evans, L.; Gettman, A.; Cuda, J. Spread of Aedes Albopictus and Decline of Ae. Aegypti (Diptera: Culicidae) in Florida. J. Med. Entomol. 1995, 32, 554-562. [CrossRef] [PubMed]

62. Cox, J.; Grillet, M.E.; Ramos, O.M.; Amador, M.; Barrera, R. Habitat Segregation of Dengue Vectors along an Urban Environmental Gradient. Am. J. Trop. Med. Hyg. 2007, 76, 820-826. [CrossRef] [PubMed]

63. Bagny, L.; Delatte, H.; Elissa, N.; Quilici, S.; Fontenille, D. Aedes (Diptera: Culicidae) Vectors of Arboviruses in Mayotte (Indian Ocean): Distribution Area and Larval Habitats. J. Med. Entomol. 2009, 46, 198-207. [CrossRef] [PubMed]

64. Barrera, R. Competition and Resistance to Starvation in Larvae of Container-Inhabiting Aedes Mosquitoes. Ecol. Entomol. 1996, 21, 117-127. [CrossRef]

65. Alto, B.W.; Lounibos, L.P.; Higgs, S.; Juliano, S.A. Larval Compettition Differentially Affect Arbovirus Infection in Aedes Mosquitoes. Ecology 2005, 86, 3279-3288. [CrossRef]

66. Murrell, E.G.; Juliano, S.A. Detritus Type Alters the Outcome of Interspecific Competition between Aedes Aegypti and Aedes Albopictus (Diptera: Culicidae). J. Med. Entomol. 2008, 45, 375-383. [CrossRef]

67. Lounibos, L.P.; O’Meara, G.F.; Juliano, S.A.; Nishimura, N.; Escher, R.L.; Reiskind, M.H.; Cutwa, M.; Greene, K. Differential Survivorship of Invasive Mosquito Species in South Florida Cemeteries: Do Site-Specific Microclimates Explain Patterns of Coexistence and Exclusion? Ann. Entomol. Soc. Am. 2010, 103, 757-770. [CrossRef] [PubMed]

68. Camara, D.C.P.; Codeço, C.T.; Juliano, S.A.; Lounibos, L.P.; Riback, T.I.S.; Pereira, G.R.; Honorio, N.A. Seasonal Differences in Density But Similar Competitive Impact of Aedes Albopictus (Skuse) on Aedes Aegypti (L.) in Rio de Janeiro, Brazil. PLoS ONE 2016, 11, e0157120. [CrossRef] [PubMed] 